\title{
Poland's syndrome associated with growth hormone deficiency
}

\author{
Daniela Larizza, Mohamad Maghnie
}

\begin{abstract}
A 9 year old boy with Poland's syndrome (absence of the left pectoralis major muscle associated with an ipsilateral malformation of the hand) and isolated growth hormone deficiency, owing to anatomical abnormalities of the pituitary gland, is described. MRI brain scan showed severe hypoplasia of both the sella and anterior lobe of the pituitary gland with absence of the pituitary stalk and ectopia of the posterior lobe. Association of Poland's syndrome and growth hormone deficiency has not been described previously.
\end{abstract}

Poland's syndrome is characterised by unilateral absence of the pectoralis major muscle associated with an ipsilateral malformation of the hand, usually syndactyly/brachydactyly. It occurs in about 1 in 20000 live births and the right side is involved in $75 \%$ of cases. ${ }^{1}$ The syndrome is usually sporadic, although familial cases have been reported. ${ }^{2}$ Poland's syndrome has been described associated with other abnormalities, including renal aplasia or hypoplasia, ${ }^{3}$ hemivertebra, ${ }^{3}$ undescended testes, ${ }^{3}$ dextrocardia, ${ }^{3}$ Moebius' syndrome, ${ }^{3}$ and 'morning glory' syndrome. ${ }^{4}$ We report a case of a boy with muscle abnormalities and short stature in whom Poland's syndrome and growth hormone (GH) deficiency were diagnosed.

\section{Case report}

The patient was first seen in the Department of Paediatrics in Pavia, Italy, at the age of 8 years 11 months for severe growth retardation. He had been born by caesarean section after a normal pregnancy. Birth weight was $3050 \mathrm{~g}$ and length $48 \mathrm{~cm}$. He had surgery for symbrachydactyly and finger webbing of the left hand at the age of 3 years and right

Clinica Pediatrica, Policlinico S Matteo, Piazzale Golgi, 27100 Pavia, Italy.

D Larizza, M Maghnie

Correspondence to Dr Larizza.

Received for publication 28 March 1989.

Revised version accepted for publication 12 June 1989. orchidopexy and reduction of an inguinal hernia at the age of 8 years. According to the parents, the boy's growth retardation started at the age of 6 years. He attended school regularly and physical activity was normal for his age. There was no evidence of psychosocial disturbances. The father and mother were unrelated. The father's height was $161 \mathrm{~cm}$ and the mother's $150 \mathrm{~cm}$. The older brother had a cleft lip. Family history was negative for endocrinopathies.

At the first admission, his height was $109 \cdot 8 \mathrm{~cm}$ (below $-3 \mathrm{SD}$ ) and weight $18.9 \mathrm{~kg}$ (below the 3rd centile according to Tanner) (fig 1). Bone age corresponded to 6 years according to the Greulich and Pyle method. Pubertal stage was P1; the volume of the right gonad was $0.5 \mathrm{ml}$ and the left $1 \mathrm{ml}$. Growth rate had been $2.4 \mathrm{~cm}$ over the preceding year (below the 3rd centile for both chronological and bone age). Clinical examination showed pectus excavatum, absence of the left pectoralis major muscle (fig 2), and hypoplasia of the left arm and hand (fig 3) with reduced mobility of the phalanges.

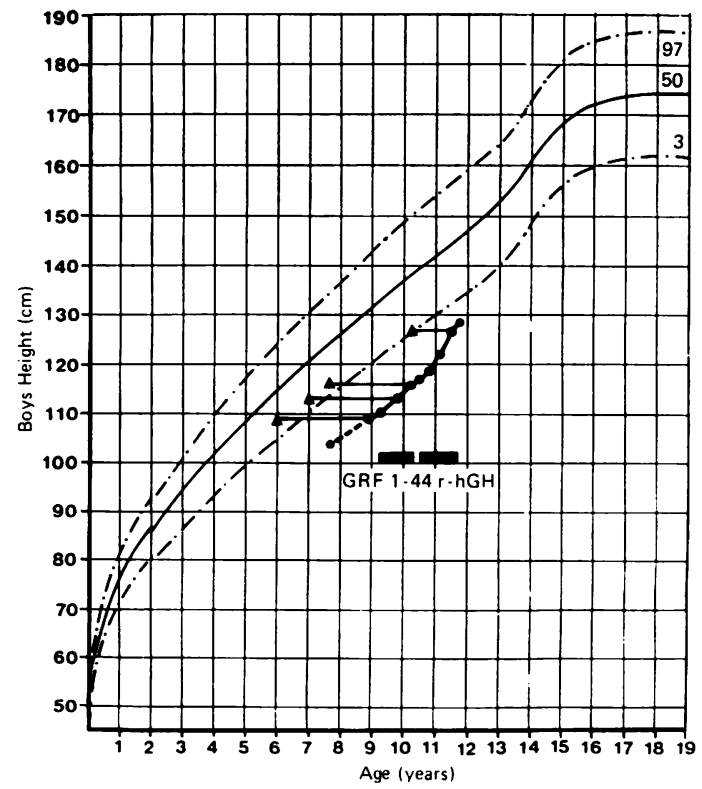

Figure 1 Patient's growth curve in relationship to the treatment. 


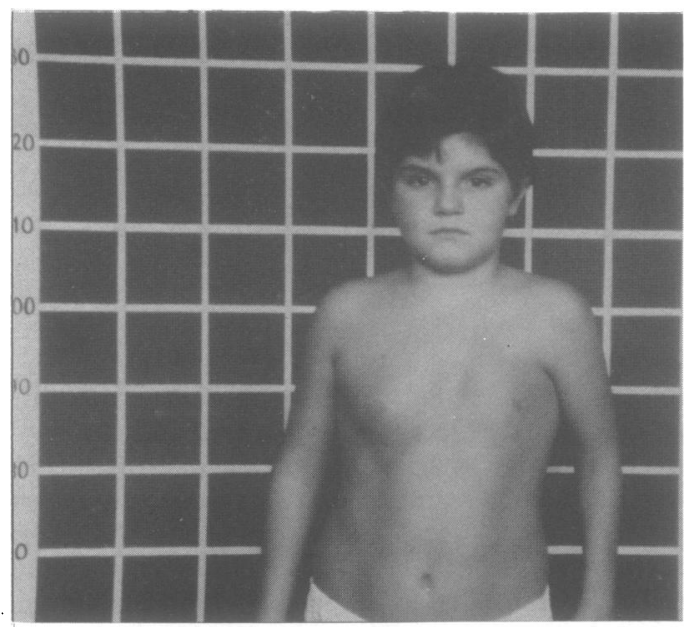

Figure 2 Patient with Poland's syndrome. Note chest deformity owing to the absence of the pectoralis muscle and abnormalities of the left hand.

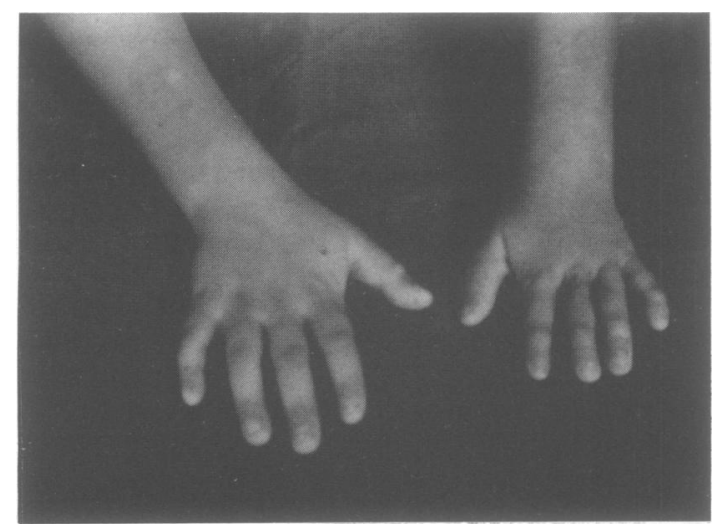

Figure 3 Patient's hands. Note acromicria and brachydactyly of the left hand.

$X$ rays of the hands showed malformations of the middle and distal phalanges of the third, fourth, and fifth fingers on the left hand. There was no evidence of other skeletal abnormalities. Ultrasound showed normal kidneys and urinary tract. Endocrinological findings are reported in the table. Fundoscopy was normal. Skull $x$ rays showed calcification of the petrosphenoid ligamenta and CT scan of the brain showed a small sella turcica. Magnetic resonance imaging showed hypoplasia of the pituitary gland, absence of the pituitary stalk, and ectopia of the posterior lobe of the pituitary.

A diagnosis was made of isolated total GH deficiency owing to a pituitary defect in a patient with
Endocrinological findings in the patient.

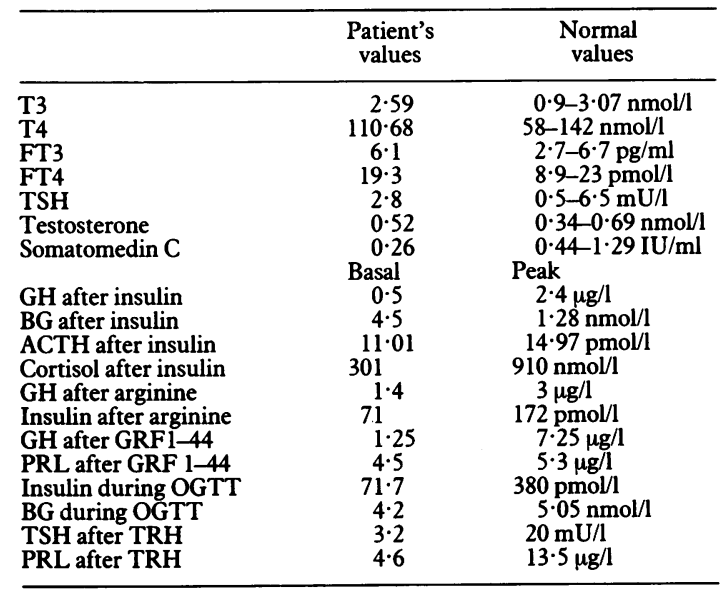

Poland's syndrome. The boy started treatment with GRF $1-44$ at the age of 9 years 4 months after informed consent had been obtained from his parents. His height increased by $5.5 \mathrm{~cm}$ after one year of therapy with GRF (fig 1). Anti-GRF antibodies remained low and somatomedin $C$ levels did not significantly increase during treatment. Because of the unsatisfactory growth rate, treatment with GRF was suspended. After three months (during which his height increased only $0.8 \mathrm{~cm}$ ), the boy started therapy with recombinant $\mathrm{GH}$ at a dose of $0.6 \mathrm{U} / \mathrm{kg}$ body weight/week subcutaneously in four doses. His growth in the first year of treatment was $10.9 \mathrm{~cm}$ (fig 1). He remains on therapy with no side effects; thyroid function and glucose tolerance remain normal.

\section{Discussion}

Poland's syndrome associated with isolated GH deficiency, as in the case reported here, has not been described previously. As short stature is not characteristic of Poland's syndrome, isolated or multiple growth hormone deficiency must be kept in mind as a possible concomitant diagnosis in patients with Poland anomalies and growth retardation.

GH deficiency has been reported in association with many anomalies and genetic syndromes characterised by growth failure, usually non-endocrine in pathogenesis, particularly in patients with midfacial defects and in diverse chromosomal abnormalities. ${ }^{5-7}$ Other findings, generally not characterised by short stature, have also been described in association with $\mathrm{GH}$ deficiency. ${ }^{5-7}$ Our patient adds one more syndrome to the list associated with GH deficiency. He has typical features of Poland's syndrome and fulfils the diagnostic criteria of GH deficiency. It is not possible 
to establish if this association in the same patient is the result of chance or is genetically determined, even if both abnormalities are congenital, as shown by the MRI brain scan findings. Although up to now there is no evidence to connect these two abnormalities, awareness of this occurrence may lead to future cases being found.

1 Smith DW. Recognizable patterns of human malformation. Genetic, embryologic and clinical aspects. Philadelphia: Saunders, 1982: 224-5.
2 David TJ, Winter RM. Familial absence of the pectoralis major, serratus anterior, and latissimus dorsi muscles. $\mathcal{F}$ Med Genet $1985 ; 22: 390-2$

3 Sugarman GI, Stark HH. Möbius syndrome with Poland's anomaly. F Med Genet 1973;10:192-6.

4 Pisteliic DT, Vranjesevic D, Apostolski S, Pisteliic DD. Poland syndrome associated with 'morning glory' syndrome (coloboma of the optic disc). $\mathcal{F}$ Med Genet 1985;22:364-6.

5 Rimoin DL. Hereditary forms of growth hormone deficiency and resistance. Birth Defects 1976; XII:15-29.

6 Kaufmann S, Jones M, Culler FL, Jones KL. Growth hormone deficiency in the Rothmund-Thomson syndrome. Am $\mathcal{F}$ Med Genet 1986;23:861-8.

7 Jorge HJ, Martinez AS, Bergada C. Etiology and association of growth hormone deficiency. Acta Endocrinol (Copenh) 1986;112 (suppl 279):113-7. 